\title{
Community health workers at the dawn of a new era: 10. Programme performance and its assessment
}

\author{
Maryse Kok ${ }^{1}$, Lauren Crigler ${ }^{2}$, David Musoke ${ }^{3}$, Madeleine Ballard ${ }^{4,5}$, Steve Hodgins ${ }^{6}$ (D) and Henry B. Perry ${ }^{7^{*}}$ (1)
}

\begin{abstract}
Background: While the evidence supporting the effectiveness of community health worker (CHW) programmes is substantial, there is also considerable evidence that many of these programmes have notable weaknesses that need to be addressed in order for them to reach their full potential. Thus, considerations about CHW programme performance and its assessment must be taken into account as the importance of these programmes is becoming more widely appreciated. In this paper, the tenth in our 11-paper series, "Community health workers at the dawn of a new era", we address CHW programme performance and how it is assessed from a systems perspective.
\end{abstract}

Methods: The paper builds on the 2014 CHW Reference Guide, a compendium of case studies of 29 national CHW programmes, the $2018 \mathrm{WHO}$ guideline on health policy and system support to optimize CHW programmes, and scientific studies on CHW programme performance published in the past 5 years.

Results: The paper provides an overview of existing frameworks that are useful for assessing the performance of CHW programmes, with a specific focus on how individual CHW performance and community-level outcomes can be measured. The paper also reviews approaches that have been taken to assess CHW programme performance, from programme monitoring using the routine health information system to national assessments using quantitative and/ or qualitative study designs and assessment checklists. The paper also discusses contextual factors that influence $\mathrm{CHW}$ programme performance, and reflects upon gaps and needs for the future with regard to assessment of $\mathrm{CHW}$ programme performance.

Conclusion: Assessments of $\mathrm{CHW}$ programme performance can have various approaches and foci according to the programme and its context. Given the fact that CHW programmes are complex entities and part of health systems, their assessment ideally needs to be based on data derived from a mix of reliable sources. Assessments should be focused not only on effectiveness (what works) but also on contextual factors and enablers (how, for whom, under what circumstances). Investment in performance assessment is instrumental for continually innovating, upgrading, and improving CHW programmes at scale. Now is the time for new efforts in implementation research for strengthening CHW programming.

Keywords: Community health workers, Performance, Monitoring, Primary healthcare

*Correspondence: hperry2@jhu.edu

${ }^{7}$ Department of International Health, Johns Hopkins Bloomberg School of Public Health, Baltimore, MD, USA

Full list of author information is available at the end of the article original author(s) and the source, provide a link to the Creative Commons licence, and indicate if changes were made. The images or other third party material in this article are included in the article's Creative Commons licence, unless indicated otherwise in a credit line to the material. If material is not included in the article's Creative Commons licence and your intended use is not permitted by statutory regulation or exceeds the permitted use, you will need to obtain permission directly from the copyright holder. To view a copy of this licence, visit http://creativecommons.org/licenses/by/4.0/. The Creative Commons Public Domain Dedication waiver (http://creativeco mmons.org/publicdomain/zero/1.0/) applies to the data made available in this article, unless otherwise stated in a credit line to the data. 


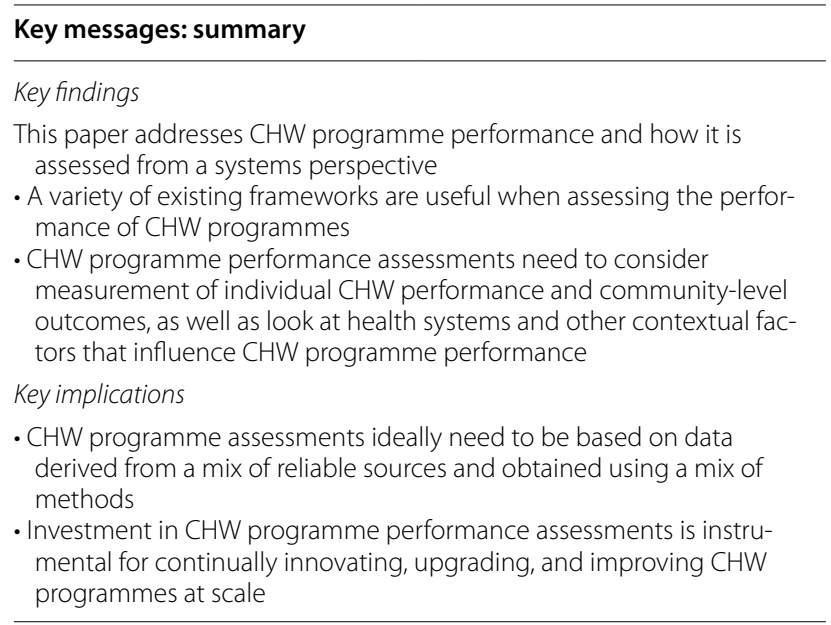

\section{Background}

This is the tenth paper in our series, "Community health workers at the dawn of a new era". Previous papers have provided an overview of national community health worker $(\mathrm{CHW})$ programmes at present and the challenges they face (Paper 1 [1]), approaches to building partnerships, collaborations, and governance (Papers 2 [2] and 3 [3]), financing (Paper 4 [4]), roles and tasks (Paper $5[5]$ ), recruitment and training (Paper 6 [6]), supervision (Paper 7 [7]), motivation and reimbursement (Paper 8 [8]), and relationships with communities and with health systems (Paper 9 [9]). This series has been produced in recognition that $\mathrm{CHW}$ programmes are in a historical moment where the importance of their contribution to health systems and to population health improvement is becoming more widely recognized [10]. Rather than being an underfunded afterthought, CHWs need to be understood as an integral part-if not the foundation-of health systems, particularly (but not exclusively) in low- and middle-income countries (LMICs) [11, 12].

This historical moment has been produced by several powerful and concurrent circumstances. First, the evidence of the effectiveness of trained and supported CHWs in providing quality health services and improving population health continues to grow [13]. Countries that are making the strongest gains in improving the health of their populations have strong $\mathrm{CHW}$ programmes, such as Bangladesh, Brazil, Ethiopia, Nepal, and Rwanda [14]. Second, the Declaration of Alma-Ata [15], which was the first major global health document to assert the importance of CHWs in 1978, was reaffirmed on its 40th anniversary in the 2018 Declaration of Astana [16]. On this anniversary, the World Health Organization (WHO) for the first time created a guideline for optimizing the contribution of $\mathrm{CHW}$ programmes to health systems $[10,17]$. The following year, the Director-General of
WHO and the World Health Assembly strongly affirmed the importance of CHWs for achieving universal health coverage and strengthening primary healthcare (PHC) $[18,19]$. Finally, the COVID-19 pandemic has clearly demonstrated the need for health workers at the community level who can prevent, detect, and respond [20,21]. The pandemic has led to calls throughout the world for CHWs to receive appropriate respect and status (including pay), not to mention the personal protective equipment that is essential for them to carry out their duties safely [22]. The pandemic has also led to broad recognition of the importance of CHWs in high-income countries [23, 24].

Improved investment and integration of $\mathrm{CHW}$ programmes in the health sector in LMICs require evidence on performance. This again requires monitoring and evaluation. The performance of CHW programmes is influenced by support (or the lack thereof) from two sides-the health sector and the community. It is also influenced by the broader social, economic, and political context [25-27]. Performance can be measured at the individual $\mathrm{CHW}$ level as well as at the programme and population level [25, 27, 28]. As discussed in Paper 1 of this series, CHWs are embedded in the community health system, which is a subsystem of the overall health system [29]. This makes the assessment of overall CHW programme performance a complex undertaking because of the number of (formal and informal) actors involved and the many relationships and processes at play in improving health at the community level. It is therefore difficult to specifically attribute CHWs' impact on health outcomes. Nevertheless, monitoring and evaluation of $\mathrm{CHW}$ programmes is of utmost importance to be able to continuously improve CHW programming and build more evidence on what works, why, and in which context [30].

\section{Key message 1}

While the assessment of $\mathrm{CHW}$ programme performance is a complex undertaking, it is of utmost importance to be able to continuously improve $\mathrm{CHW}$ programming

\section{Methods}

In this discussion paper, we address $\mathrm{CHW}$ programme performance and how it is assessed from a systems perspective, acknowledging that health systems are complex social arrangements [31]. We start by defining $\mathrm{CHW}$ and $\mathrm{CHW}$ programme performance, after which we reflect upon various frameworks that have been developed for considering the performance of $\mathrm{CHW}$ programmes. Next, we provide an overview of approaches to assessing $\mathrm{CHW}$ programme performance, and finally, we reflect 
upon identified gaps and needs for the future with regard to assessment of $\mathrm{CHW}$ programme performance.

This paper builds on previous work of our writing team, most notably the widely used 2014 CHW Reference Guide, which targeted CHW programme managers and policymakers, supporting them in developing and strengthening $\mathrm{CHW}$ programmes at scale [12]. It is also informed by a recently released compendium of case studies of 29 national $\mathrm{CHW}$ programmes [14]. In addition, the WHO guideline on health policy and system support to optimize CHW programmes (2018) is discussed in this paper, as this recent guidance not only aims to assist national governments and national and international partners in improving the design and implementation of CHW programmes, but also aims to improve their performance and evaluation [17]. We also discuss the CHW Assessment and Improvement Matrix (AIM) toolkit [32, 33]. Lastly, we include illustrative examples of studies on CHW programme performance and community health information systems (CHIS) published in the past 5 years (i.e., since publication of the CHW Reference Guide). For this purpose, we conducted a search on PubMed in August 2020, with a broad focus on CHWs, performance, information systems, and LMICs. We used a wide definition of CHWs, which includes a spectrum extending from volunteers with brief informal training to paid, professionalized CHWs, as outlined in Paper 1 of this series [1]. The 551 search results were screened on their titles and abstracts, and examples of partial or full $\mathrm{CHW}$ programme assessments, conducted with a variety of methods, were taken up in this paper to illustrate the discussion.

\section{Results}

\section{Defining $\mathrm{CHW}$ and $\mathrm{CHW}$ programme performance}

Well-performing health workers function in ways that are responsive, fair, and efficient to achieve the best health outcomes possible for clients, given the available resources and circumstances [34]. We use this definition of health worker performance for CHWs as well and stress that for CHWs to be responsive, fair, and efficient in achieving the best health outcomes in their communities, the available support from and relationships with actors in the health sector and the community are instrumental.

CHW performance at the individual CHW level is the sum of different interrelated attributes, such as knowledge, guideline adherence, competencies, motivation, job satisfaction, agency, attitudes, and self-esteem [25]. These attributes can be measured in various wayssome more difficult than others-and can thereby give an indication of $\mathrm{CHW}$ programme performance. However, $\mathrm{CHW}$ programme performance is not only the sum of performance-related individual attributes of CHWs; it is also defined by community-level outcomes, such as health service use and community empowerment, and, ultimately, health outcomes (impact) $[25,27,28]$. We will explore this in the next section.

\section{CHW programme performance frameworks}

Over the past decade, several frameworks on $\mathrm{CHW}$ programme performance have been published. While these frameworks differ in terminology used and sometimes in focus, all address determinants of CHW individual and programme performance. We draw on three of these in this paper: Kok et al's framework of intervention design factors influencing CHW performance [25], Naimoli et al's CHW logic model [27], and Agarwal et al's conceptual framework for measuring $\mathrm{CHW}$ performance within PHC systems [28].

Agarwal et al. (2019) [28] recently developed a CHW performance measurement framework using the common input-process-output-outcome logic model approach, while recognizing that community health systems are nonlinear and complex. Determinants of CHW programme performance are presented as inputs and programmatic processes. The inputs include policies (e.g., $\mathrm{CHW}$ selection procedures and CHW roles and tasks), governance and stakeholders, logistics (e.g., transport and commodities), funding, and information management systems. Other widely used frameworks label these as health systems factors $[25,27]$. The programmatic processes entail supportive systems (e.g., supervision, performance appraisal, and data use), CHW development (e.g. recruitment, training, and incentives), and support from community-based groups [28].

Naimoli et al. (2014) [27] label these as programmelevel activities, where they distinguish technical support, social support, and incentives from the perspective of both health sector actors and community actors. In Kok et al.s (2015) [25] conceptual framework on factors influencing CHW performance, these are labelled as intervention design factors; in Ballard and Montgomery's (2016) systematic review, they are called intervention components [35]. These determinants of CHW programme performance are important, and we will come back to them later in this paper. We now focus on how performance can be defined and measured.

As indicated above, most frameworks make a distinction between individual $\mathrm{CHW}$ performance and community-level outcomes as indicators of $\mathrm{CHW}$ programme performance. Between the frameworks, the categorization of the attributes of individual $\mathrm{CHW}$ performance differs, but the attributes themselves are in line with each other. Following the categorization (indirect and direct) used in the work of Naimoli et al. (2014) [27], Table 1 
contains the attributes of individual CHW performance from the three frameworks combined [25, 27, 28]. Some of these attributes slightly overlap. What is important, though, is how the attributes are operationalized, and this will vary by country and programme context. In the next section, we discuss how they could be measured.

The three frameworks cover community-level outcomes as indicators of $\mathrm{CHW}$ programme performance. Naimoli et al. (2014) [27], unlike the others, distinguish CHW-attributable changes among individual clients, in the community, and in health systems. For example, CHWs could influence changes in health system structures, processes, and behaviours. In Table 2, we list community-level outcomes reported across the three frameworks. They include outcomes that can relate to individual community members and communities more broadly. Some of them overlap, and again, their usefulness depends on how they are operationalized in the context of a specific CHW programme.

The performance of individual CHWs and the community-level outcomes will (ideally) lead to improved health outcomes at the population level (impact): equitable reductions in mortality and morbidity, improved well-being, reduced disease incidence, or changes in the incidence of health-related conditions (such as teenage pregnancy) (Fig. 1). While changes in population-level health indicators are readily measurable, attributing any observed changes to the impact of $\mathrm{CHW}$ programmes is a challenging methodological task and is often difficult in the absence of evaluations that have a control area where the CHW programme was not present. In addition, other influences that are producing measurable improvements in population health are also present, such as improved socioeconomic conditions and facility-based healthcare.

Key message 2
CHW programme performance assessments need to consider measure-
ment of individual CHW performance, community-level outcomes,
and impact at the population level

\section{Approaches to assessing $\mathrm{CHW}$ programme performance} Depending on the programme and evaluation focus, a combination of the above-presented attributes of individual CHW performance and community-level outcomes can be included for assessing CHW programme performance. Different methods are suitable for this, depending upon the attribute or outcome and associated indicators.

\section{The use of meeting minutes, training and accreditation logs, and reports from $\mathrm{CHWs}$ and supervisors}

$\mathrm{CHW}$ programmes often have mechanisms for reporting which are different from data captured in the routine health information system. Minutes of meetings

Table 1 Indirect and direct attributes of individual CHW performance [25, 27, 28]

\begin{tabular}{|c|c|c|}
\hline Category & CHW attribute & Definition \\
\hline \multirow[t]{10}{*}{ Indirect } & Agency/empowerment & $\begin{array}{l}\text { The CHW's capacity to make purposeful choices and transform these into desired actions and outcomes (derived } \\
\text { from the definition of empowerment by Petesch et al. [36]) }\end{array}$ \\
\hline & Adherence to guidelines & Degree to which the CHW adheres to programme guidelines \\
\hline & Attitude & $\begin{array}{l}\text { The CHW's attitudes toward the client, community, other health workers, the employer, and organization for } \\
\text { which s/he is working }\end{array}$ \\
\hline & Competencies & $\begin{array}{l}\text { Degree to which the CHW has the skills (e.g., in communication, diagnosis, treatment, referral, advocacy) neces- } \\
\text { sary to carry out the tasks assigned to him/her }\end{array}$ \\
\hline & Engagement & Degree to which the CHW enjoys and believes in what s/he does and feels valued for doing it [37] \\
\hline & (Job) satisfaction & Degree to which the CHW derives personal satisfaction from his/her role/job \\
\hline & Knowledge & $\begin{array}{l}\text { Degree to which the CHW has the theoretical or practical understanding of the function and tasks assigned to } \\
\text { him/her }\end{array}$ \\
\hline & Morale & $\begin{array}{l}\text { The mental and emotional condition (enthusiasm, confidence, etc.) of a CHW with regard to the function or tasks } \\
\text { at hand }\end{array}$ \\
\hline & Motivation & A CHW's degree of willingness to exert and maintain effort on assigned tasks \\
\hline & Self-esteem/efficacy & A CHW's confidence, belief in his/her ability to produce an expected, desired result \\
\hline \multirow[t]{6}{*}{ Direct } & Absenteeism & The rate at which CHWs do not carry out the assigned tasks \\
\hline & Attrition & The rate at which practicing CHWs resign, retire, or abandon their positions \\
\hline & Productivity & A CHW's output of services/tasks \\
\hline & Responsiveness & The degree to which a CHW responds to the needs of clients or groups within a reasonable time period \\
\hline & Service delivery & Quantity of promotional, preventive, and curative services CHWs provide to community members \\
\hline & Service quality & $\begin{array}{l}\text { The degree to which CHWs provide promotional, preventive, and curative services according to quality standards } \\
\text { and procedures }\end{array}$ \\
\hline
\end{tabular}


Table 2 Community-level outcomes as measurements of CHW programme performance [25, 27, 28]

\begin{tabular}{|c|c|}
\hline Outcome & Definition \\
\hline Access & $\begin{array}{l}\text { Equitable physical and social access to essential services delivered by CHWs, or delivery of services in a } \\
\text { timely manner within the client's home }\end{array}$ \\
\hline Community functioning & $\begin{array}{l}\text { (Changes in) a community's structure, processes and behaviours resulting from its interaction with a } \\
\text { CHW }\end{array}$ \\
\hline Community empowerment & Degree to which both individuals and communities participate actively in community health activities \\
\hline Cost savings & $\begin{array}{l}\text { Money not spent by community members or by the community that otherwise would have been spent } \\
\text { in the absence of a CHW }\end{array}$ \\
\hline Credibility & $\begin{array}{l}\text { Degree to which the community considers CHWs to be making an important and valuable contribution } \\
\text { to the health and well-being of the community }\end{array}$ \\
\hline Health-promoting behaviour & $\begin{array}{l}\text { Community members or communities have adopted health-promoting behaviours at home or in the } \\
\text { community as a result of contact with CHWs }\end{array}$ \\
\hline Knowledge of service availability & $\begin{array}{l}\text { Community members' ability to identify the location of } \mathrm{CHWs} \text {, the services they provide, and when they } \\
\text { are available }\end{array}$ \\
\hline Prestige & $\begin{array}{l}\text { Status the community confers upon } \mathrm{CHWs} \text { as a result of their selection and/or resulting from the quan- } \\
\text { tity and quality of the services they deliver to community members }\end{array}$ \\
\hline Referral/counter referral & $\begin{array}{l}\text { Degree of acceptance and use of services provided at a health facility following referral by a CHW, and } \\
\text { the degree of acceptance and use of CHW services when referred back to the CHW by the health } \\
\text { facility }\end{array}$ \\
\hline Satisfaction & Clients' or communities' reported degree of satisfaction with the services rendered by CHWs \\
\hline Social cohesion & $\begin{array}{l}\text { Change in the manner in which community members work towards achieving a goal or satisfy the } \\
\text { emotional needs of its members (including marginalized or vulnerable groups) resulting from its } \\
\text { interaction with a CHW }\end{array}$ \\
\hline Trust & $\begin{array}{l}\text { Degree to which community members or communities believe that the CHW will do his/her best to } \\
\text { meet their needs [38] }\end{array}$ \\
\hline Use of services/healthcare-seeking behaviour & $\begin{array}{l}\text { Degree to which community members (including marginalized or vulnerable groups) with access to } \\
\text { CHWs are routinely seeking and using promotional, preventive, and curative services that CHWs offer }\end{array}$ \\
\hline
\end{tabular}

Disease incidence
Incidence of other health-related conditions (such as teenage pregnancy) Nutritional status

$>\longrightarrow \begin{gathered}\text { Mortality } \\ \text { Morbidity } \\ \text { Well-being }\end{gathered}$

Fig. 1 Impact at the population level of CHW programme performance between CHWs and supervisors, or of village health or other committees involving CHWs, can provide insight into, for example, CHW satisfaction or productivity and their influencing factors. Training and accreditation logs, if available, can provide information about (gained) knowledge of CHWs. Supervisor reports and standardized checklists can include observations on guideline adherence and quality of care provided by CHWs [28, 39]. Supervisor reports can provide useful quantitative data if there is regular supervision of all CHWs, because infrequent supervision or supervision of only a part of the CHW workforce may distort indicator measurement [40].

There are various examples of studies in the recent academic literature in which these types of data are used to assess CHW performance, sometimes combined with data from other sources, such as surveys or qualitative interviews. These studies mostly focus on specific attributes of individual CHW performance in the context of vertical programmes. For example, in Nepal, Thapa et al. (2020) [41] assessed the knowledge of female community health volunteers (FCHVs) before and after a (cascade) training on postpartum family planning. They also reviewed FCHV registers, interviewed clients, and conducted focus group discussions with FCHVs. They concluded that the intervention resulted in increased knowledge and improved community-based counselling by FCHVs. However, long-term effects were not measured.

In Nigeria, Abimbola et al. (2016) [42] analysed the minutes of 129 community health committees (CHCs) across four states. These minutes provided a wealth of information about committee processes, deliberations, actions, decisions, and relations. CHCs had five modes of functioning in promoting community engagement in PHC. They provided forums (called village squares) for 
community stakeholders to interact with and support the health system, they reached out within their communities (community connectors), they lobbied governments for support (government botherers), they induced and augmented government support (back-up government), and took control of healthcare in their community (general overseers). While performing these functions, contextual factors, in particular power imbalances, limited their influence on improving health service delivery. It was therefore concluded that $\mathrm{CHCs}$ tended to promote collective action for self-support (of the committee) more than collective action for demanding accountability.

\section{The use of information from the routine health information system}

Key CHW programme activities and outputs need to be routinely documented and analysed, beginning at the most peripheral tier of the PHC system. The health information system provides a basis for this. However, the inclusion of community health services into the routine health information system varies by country. Depending on the available system, activities and outputs of CHWs can be specifically identified or not. For example, information systems may have data on referral from CHWs to health facilities. Other indicators, such as antenatal care (ANC) utilization, can be disaggregated based on whether it was offered at a community or facility level. Calculations to measure performance can then be made by comparing ANC use to the use based on the number of expected pregnancies in the CHW catchment area. If disaggregation between facility- and community-level data is not possible, it is more difficult to assess CHW programme performance.

The recent academic literature provides examples of studies that used data from routine health information systems to assess CHW performance. In Mozambique, Jose et al. (2020) [43] evaluated the role of CHWs in promoting facility-based tuberculosis (TB) screening and household contact tracing using routine national TB programme data in five intervention and seven control districts. They concluded that the involvement of CHWs led to an increase in TB notifications over the period of 1 year. In Sierra Leone, CHW reports were discussed in community health data review meetings where community leaders, members of ward development and health management committees, $\mathrm{CHW}$ peer supervisors, and representatives of the peripheral health unit assessed CHW performance and developed action plans for improvement [44].

Roberton et al. (2016) [40] examined the feasibility of collecting integrated community case management (iCCM) routine indicators as included in the $\mathrm{iCCM}$ Indicator Guide in 10 countries. They concluded that the majority of data needed are being collected through existing monitoring systems. However, they are mostly available at the health facility level and do not get aggregated at district or national level [40].

\section{The use of information from existing periodic national surveys}

National demographic and health surveys (DHSs) include indicators that provide valuable information on CHW programme performance. For example, DHS 8 woman's and man's questionnaires contain indicators such as the percentage of women visited by a $\mathrm{CHW}$ in the last 12 months and the percentage of men who discussed family planning with a CHW [45]. The United Nations Children's Fund (UNICEF) multiple indicator cluster surveys also contain questions on CHWs. For example, the questionnaire for individual women covers whether CHWs offered antenatal, delivery, and postnatal care [46]. These data can be assessed over longer periods of times (e.g., every 5 years) to get a sense of how $\mathrm{CHW}$ programme performance is evolving.

\section{Periodic internal or external $\mathrm{CHW}$ programme assessments}

Countries can readily carry out their own periodic assessments of their national $\mathrm{CHW}$ programmes. One possible approach to this is national evaluation platforms (NEPs) that have been developed in some countries. NEPs build national capacity to systematically identify, compile, and rigorously analyse data from diverse sources to evaluate the effectiveness of maternal, newborn, and child health and nutrition programmes [47]. Efforts such as these could be adapted to assess national CHW programme performance. There are examples of countries that, often with funding from external donors, contract firms to carry out independent assessments of national CHW programmes as is commonly done with other development projects. For example, the health extension programme in Ethiopia was evaluated in 2018-2019 [48]. The national assessment consisted of a comprehensive mixed-methods study, a systematic review, and a participatory process to synthesize evidence and develop recommendations. The assessment revealed the strengths and weaknesses of the programme. Amongst others, it found gaps in health extension worker competencies as a result of suboptimal pre-service training. In 2011, a mixed-methods national assessment of $\mathrm{CHW}$ services in Afghanistan was conducted. It was found that training, supervision, and supplies were adequately organized, mainly by implementing nongovernmental organizations, but overload and motivation of CHW were issues of concern [49]. Other examples of national CHW programme assessments are provided in Table 4 (Appendix). 


\section{The use of primary studies and research tools}

Primary studies often focus on a limited set of attributes or outcomes related to $\mathrm{CHW}$ programme performance. In addition, they often look at vertical CHW programmes. They are seldom applied to national and scaled CHW programmes. As mentioned in Paper 1 of this series, evidence from small-scale studies can still be relevant for large-scale programmes.

Primary studies can have various methodologies. Randomized controlled trials (RCTs) often assess the effect of a change in supportive systems, such as certain modalities of $\mathrm{CHW}$ supervision or incentives, on attributes of individual CHW performance, such as guideline adherence or productivity $[50,51]$, or community-level outcomes such as service use [52]. While RCTs are needed for robust evidence, the RCT design is relatively unhelpful in providing full assessments of complex programmes at scale. Comprehensive programme case studies are a useful addition, as well as implementation research, using surveys over time, scales, qualitative methods, and systems-thinking tools [17].

When using surveys to measure attributes or outcomes on CHW (programme) performance, researchers can consider numerous indicators, according to the CHW programme under study and its context. Agarwal et al. (2019) [28] provide example indicators in their work based on a review of peer-reviewed articles, reports and global data collection tools, and consultations with global stakeholders, community health implementers, advocates, measurement experts, and ministry of health representatives across seven countries. One possible indicator of productivity and the use of services is the household visitation rate. Mwanza et al. (2017) [53] reported on $\mathrm{CHW}$ supervisors using the lot quality assurance sampling (LQAS) methodology to evaluate $\mathrm{CHW}$ performance in terms of household visitation rate in Zambia. LQAS proved to be a useful tool to assess CHW performance and could be used for performance appraisal as well. Smittenaar et al. (2020) conducted large-scale surveys including recently delivered women, their husbands, mothers-in-law, and accredited social health activists (ASHAs) in Uttar Pradesh, India. Household visitation timing and rate, ASHAs' knowledge and beliefs, and the content and target of their advice were found to influence maternal and newborn health-promoting and healthseeking behaviour [54].

With regard to scales on attributes of individual $\mathrm{CHW}$ performance, one can adjust existing scales developed for other purposes unrelated to CHWs to the context of $\mathrm{CHW}$ programmes. The engagement survey for measuring the well-being of workers is one example [55]. The engagement survey asks employees to rate items on: their belief in their work and organization; their belief in their ability to succeed; their relations with colleagues and their supervisor; their opportunities for professional advancement; the support and recognition they receive; and the influence they have in decision-making. Another valuable toolkit that can be used to measure attributes of individual CHW performance is CUBES, which focuses on contextual and perceptual drivers (including beliefs, such as self-efficacy) of behaviour [56].

Recently, a validated scale for measuring motivation specifically for CHWs was published, consisting of 12 items related to job satisfaction, organizational commitment, community commitment, and work conscientiousness [57]. Qualitative methods, along with quantitative scales or as a stand-alone method, can provide insight into $\mathrm{CHW}$ performance as well.

For example, Kane et al. (2016) [58] presented findings from six country case studies from Africa and Asia regarding $\mathrm{CHW}$ empowerment. Their analysis was based on Lee and Koh's analytical framework of empowerment that identifies four dimensions of empowerment: meaningfulness, competence, self-determination, and impact. The study found CHWs had feelings of empowerment as well as disempowerment. The authors recommend that more attention should be given to the experience of CHWs when aiming for improving CHW programme performance. We fully support this statement, as it is obvious that addressing issues of concern to $\mathrm{CHWs}$ themselves is an essential strategy for improving overall CHW programme performance. Vareilles et al. (2015) [59] conducted a realist evaluation on motivation of community health volunteers of the Red Cross in Uganda. They describe how a supportive environment positively influenced three key drivers of volunteer motivation: feelings of autonomy, competence, and connectedness.

For measurement of community-level outcomes, community scorecards can be used, where communities score on performance indicators [60]. With this method, outcomes such as satisfaction with CHW services, and communities' trust in and perceptions of credibility of CHWs can be assessed. In addition, a variety of qualitative methodologies can be used.

\footnotetext{
Key message 3

Approaches to assessing CHW programme performance can include monitoring based on available data in the health system, and primary studies or national programme assessments that use a variety of methods
}

CHW programme assessments: a focus on programmatic determinants of performance

Programme inputs, as mentioned before, entail policies, governance and stakeholders, logistics, funding, and 
information management systems. Programmatic processes entail supportive systems, CHW development, and support from community-based groups. Many studies focus on these inputs and processes-either one or all of them-because they influence $\mathrm{CHW}$ programme performance. Therefore, regular assessment of these programmatic determinants of performance provides information on whether a $\mathrm{CHW}$ programme is designed and being implemented in such a way as to yield good performance.

\section{The WHO guideline}

Based on available global evidence-including a systematic review of published literature reviews [61], 15 systematic reviews of relevant primary studies, and a stakeholder perception survey-the 2018 WHO guideline on health policy and system support to optimize $\mathrm{CHW}$ programmes $[10,17]$ provides recommendations on 15 programmatic determinants of performance. These are: selection of CHWs, duration of their pre-service training, competency domains for the curriculum for pre-service training, modalities of pre-service training, competency-based certification, supportive supervision, remuneration, contracting agreements, career ladder, target population size, data collection and use, types of CHWs, community engagement, and mobilization of community resources. Depending on the certainty of evidence about positive effects on $\mathrm{CHW}$ programme performance, WHO provides conditional or strong recommendations about the design of these programme components. While most recommendations are conditional, a strong recommendation is made for establishing robust community engagement strategies. WHO also strongly recommends remunerating practising CHWs for their work with a financial package commensurate with the job demands, complexity, number of hours, training, and roles that they undertake; and providing paid CHWs with a contracting agreement specifying role and responsibilities, working conditions, remuneration, and workers' rights. Although evidence regarding the benefits of remuneration was of low certainly, these recommendations were made based on human and labour rights [17].

\section{The CHW AIM toolkit}

While the WHO guideline provides recommendations and considerations for optimization of the design, implementation, and performance of $\mathrm{CHW}$ programmes, it does not provide specific tools or checklists to assess the extent to which a current programme design can yield optimal performance. The often used CHW Assessment and Improvement Matrix (AIM) toolkit, developed in 2011 and updated in 2018, serves this goal [32, 33]. The updated toolkit contains a programme functionality matrix with 10 programme components that influence performance of CHW programmes: role and recruitment, training, accreditation, equipment and supplies, supervision, incentives, community involvement, opportunity for advancement, data, and linkages to the national health systems (Table 3). It is clear that these 10 programme components cover the 15 components included in the WHO guideline, as listed in the previous paragraph.

Table 3 Programmatic components of the updated CHW AIM tool [63]

\begin{tabular}{|c|c|c|}
\hline & Component & Description \\
\hline 1 & Role and recruitment & $\begin{array}{l}\text { How the community, } \mathrm{CHW} \text {, and health system design and achieve clarity on the CHW role and from } \\
\text { where the } \mathrm{CHW} \text { is identified and selected }\end{array}$ \\
\hline 2 & Training & $\begin{array}{l}\text { How pre-service training is provided to the } \mathrm{CHW} \text { to prepare for his/her role and ensure s/he has the nec- } \\
\text { essary skills to provide safe and quality care; and how ongoing training is provided to reinforce initial } \\
\text { training, teach CHWs new skills, and to help ensure quality }\end{array}$ \\
\hline 3 & Accreditation & $\begin{array}{l}\text { How health knowledge and competencies are assessed and certified prior to practicing and recertified at } \\
\text { regular intervals while practicing }\end{array}$ \\
\hline 4 & Equipment and supplies & How the requisite equipment and supplies are made available when needed to deliver expected services \\
\hline 5 & Supervision & $\begin{array}{l}\text { How supportive supervision is carried out such that regular skill development, problem solving, perfor- } \\
\text { mance review, and data auditing are provided }\end{array}$ \\
\hline 6 & Incentives & $\begin{array}{l}\text { How a balanced incentive package reflecting job expectations, including financial compensation in the } \\
\text { form of a salary, and nonfinancial incentives, is provided }\end{array}$ \\
\hline 7 & Community involvement & How a community supports the creation and maintenance of the CHW programme \\
\hline 8 & Opportunity for advancement & How CHWs are provided career pathways \\
\hline 9 & Data & $\begin{array}{l}\text { How community-level data flow to the health system and back to the community and how they are used } \\
\text { for quality improvement }\end{array}$ \\
\hline 10 & Linkages to the national health system & $\begin{array}{l}\text { The extent to which the ministry of health has policies in place that integrate and include CHWs in health } \\
\text { system planning and budgeting and provides logistical support to sustain district, regional, and/or } \\
\text { national CHW programmes }\end{array}$ \\
\hline
\end{tabular}


Each of the 10 components is subdivided into four levels of functionality: $1=$ nonfunctional, $2=$ partially functional, $3=$ functional, and $4=$ highly functional. For each of the programme components, each functionality level is described by situations commonly seen in $\mathrm{CHW}$ programmes, so that assessors can match the status of the CHW programme components against these descriptions to guide their assessment. For example, with regard to the component supervision, it goes from CHWs not or very occasionally being visited by supervisors or other health staff (score 1) to monthly, supportive supervision by dedicated and trained supervisors (score 4). The CHW AIM toolkit has been used by governmental, nongovernmental, and other stakeholders in the assessment, improvement, and planning of $\mathrm{CHW}$ programmes. Recently, it was used for the evaluation of the CORE Group Polio Project over a 20-year period in five countries. The successful programme, which made use of community mobilizers (CHWs), met the basic level of functioning (level 3) for six of the 10 components of the AIM tool [62].

\section{Other ways to assess programmatic determinants of performance}

Assessment of logistics and human resources can be informed by data on commodity availability from the logistics information system and by data on, for example, training and certification of CHWs from the human resources information system. Recently, a validated scale on perceived $\mathrm{CHW}$ supervision was published, containing six items that cover perceptions of CHWs on how they are supervised [64].

\section{Key message 4}

The 2018 WHO guideline [17] (2018) and the AIM toolkit [32, 33] provide guidance to assess a list of main programme components that influence CHW programme performance

\section{Contextual factors influencing $\mathrm{CHW}$ programme performance}

As stated in the Background of this paper, $\mathrm{CHW}$ programme performance is also influenced by the broader context. While it is not possible to change the context, at least in the short term, it is important to understand how certain contextual factors influence $\mathrm{CHW}$ programme components, attributes of individual $\mathrm{CHW}$ performance, and community-level outcomes. This can contribute to adjusting the programme to better fit in or respond to the context, resulting in better programme performance.

Kok et al. (2015) [65] conducted a literature review on contextual factors that influence $\mathrm{CHW}$ performance. The factors were categorized into the community context, economic context, environment, health system policy, and health system practice. The community context includes sociocultural factors (such as gender norms and values as well as disease-related stigma), safety and security, and knowledge of the target group. The environment includes geography and climate. The health system policy includes the existence of a $\mathrm{CHW}$ policy, human resource policy, legislation related to $\mathrm{CHWs}$, and political commitment. Finally, a set of health system factors plays a role in influencing performance (health service functionality, human resource provisions, level of decision-making, costs of health services, and the governance and coordination structure). These factors should be taken into account when assessing $\mathrm{CHW}$ programme performance. As a recent example, Marston et al. (2020) [66] used qualitative research to provide insights into how family planning services offered by FCHVs in Nepal could be more tailored to the community context. For example, the study showed the importance of FCHVs upholding secrecy and privacy in their interactions with women to increase health-seeking behaviour. Bergström et al. [67] developed the Context Assessment for Community Health $(\mathrm{COACH})$ tool, which is based on the PARIHS [Promoting Action on Research Implementation in Health Services] framework [68]. The COACH tool can be used to map and measure aspects of the local healthcare context that can influence the implementation of evidence-based interventions, including $\mathrm{CHW}$ programmes, in LMICs [67].

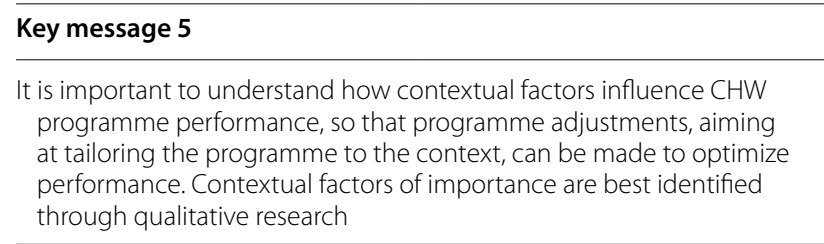

\section{Gaps and needs for the future}

This paper has focused on CHW programme performance and how this could be assessed. Performance assessments will differ by programme, as programmes have different features, in particular with regard to the types of CHWs, the services they provide, and their support mechanisms. As such, standardization of assessments of CHW programme performance is only possible to a certain extent. Given the fact that large-scale CHW programmes are complex entities and part of health systems, their assessment ideally needs to be based on data derived from a mix of reliable sources.

While it is useful and efficient to use existing data sources, such as routine health information systems, these sources have limitations. We already pointed out that in many settings, community-based data cannot be 
disaggregated from facility-based data. Routine health information systems often fail to capture data on services provided solely at a community level [30], and human resource information systems similarly do not always capture data on CHWs, especially when they are volunteers.

In addition, there are indications that data are not always reliable. Data collectors, including CHWs, sometimes see data collection and reporting as a "tick-the-box exercise", because it concerns mere reporting up into the administrative ether rather than reporting data that are used at different levels to improve services delivery [69]. Feedback loops are often lacking. Regeru et al. (2020) [70] found that in Kenya and Malawi, there were large discrepancies between data reported by CHWs and those reported by their supervisors. Barriers to the reporting of high-quality data were (1) unavailability of standard data collection and reporting tools, (2) limited training of CHWs on data reporting, (3) parallel reporting requirements of vertical programmes, and (4) overload of CHWs tasks leading even to fabrication of data. In the study in Sierra Leone mentioned earlier, it was also found that $\mathrm{CHW}$ reported morbidity and mortality data were of low quality and incomplete [44].

CHISs need strengthening. Data quality assessments can stimulate improvements, as shown in the Democratic Republic of the Congo, Malawi, Mozambique, Niger, and Nigeria in relation to iCCM [71]. Digital data collection also provides opportunities for improvement of routine data collection, quality, and use [72, 73].

Maher and Cometto (2016) [74] have pointed out that research on CHWs should be focused not only on effectiveness (what works) but also on contextual factors and enablers (how, for whom, under what circumstances). George et al. (2018) [75] argue-and we underline thisthat efforts to strengthen CHW programmes must "guard against the hubris of relying on a single approach or hierarchy of evidence". Instead, understanding the implementation realities of $\mathrm{CHW}$ programmes will require "humility in understanding communities as social systems, the complexity of the interventions they engage with and the heterogeneity of evidence needs that address the implementation challenges faced". Most research on CHW programmes has had a narrow focus on a specific disease or intervention, and research on large-scale integrated $\mathrm{CHW}$ programmes remains limited. The WHO guideline calls for new health policy and systems methodologies such as implementation research, systems thinking tools, process monitoring, and rapid synthesis of available research [17]. Agarwal et al. (2019) [76] have carried out a literature and consultative review to identify evidence gaps about community health systems and to propose a research agenda to strengthen $\mathrm{CHW}$ programmes. Priority research questions they identified included queries on (1) the most effective and efficient supervision and monitoring systems to improve CHW performance, (2) the added value of the use of digital technologies in supervision and monitoring, (3) policies, financing, and governance structures required to support and sustain CHW programmes, (4) CHW models that improve cost-effectiveness and quality of care, and (5) which combinations of training, incentives, and career growth opportunities increase $\mathrm{CHW}$ motivation and retention.

Looking at the attributes of individual CHW performance, community-level outcomes and impact at the population level (Tables 1-2, Fig. 1), it is obvious that the academic literature addresses many of these, but others are relatively neglected. More attention to communitylevel outcomes, such as empowerment and trust, is needed when we aim to fully understand how performance is shaped in different contexts. We also need to recognize that certain CHWs working for a programme may face different factors that influence their performance than other $\mathrm{CHWs}$ in the same programme and therefore need different types of support; there is no one-size-fits-all approach to improving CHW performance. As there is evidence that $\mathrm{CHW}$ programmes reduce inequities in access to services and promote inclusion of marginalized or vulnerable groups [77], there is also a need to disaggregate metrics to be able to assess for equity. Lastly, as referred to above, it is important to improve methods in assessing cost-effectiveness of CHW programmes [78].

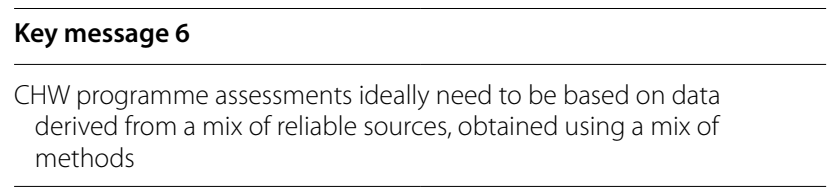

\section{Conclusion}

Assessments of CHW programme performance can have various approaches and foci according to the programme and its context. Given the fact that $\mathrm{CHW}$ programmes are complex entities and part of health systems, their assessment ideally needs to be based on data derived from a mix of reliable sources. Assessments should be focused not only on effectiveness (what works) but also on contextual factors and enablers (how, for whom, under what circumstances). Serious attention to assessments is instrumental for continually innovating, upgrading, and improving $\mathrm{CHW}$ programmes at scale. Programmes will need steadily increasing funding to be able to respond to the gaps and needs identified. Now is the time for a new frontier of implementation research for strengthening $\mathrm{CHW}$ programming. 


\section{Appendix}

See Table 4.

Table 4 The overview below is derived from the book "Health for the People: National Community Health Worker Programs from Afghanistan to Zimbabwe" (2020). It contains basic information on availability of information systems and national performance assessments of the respective CHW programs. Where cells are left blank, this means No or Unknown

\begin{tabular}{|c|c|c|}
\hline Country & $\begin{array}{l}\text { (Selected) household and service delivery data collected by CHWs feed } \\
\text { into national level information systems }\end{array}$ & $\begin{array}{l}\text { Large scale national CHW program } \\
\text { performance assessment(s) } \\
\text { conducted }\end{array}$ \\
\hline Afghanistan & Yes & Yes [49] \\
\hline \multicolumn{3}{|l|}{ Bangladesh } \\
\hline Brazil & Yes & Yes [79] \\
\hline Ethiopia & Yes & Yes [48] \\
\hline Ghana & Yes & \\
\hline India & & Yes [80] \\
\hline \multicolumn{3}{|l|}{ Indonesia } \\
\hline Iran & Yes & \\
\hline Kenya & Yes & Yes [81] \\
\hline Liberia & Yes & \\
\hline Madagascar & Yes & \\
\hline Malawi & Yes & \\
\hline \multicolumn{3}{|l|}{ Mozambique } \\
\hline \multicolumn{3}{|l|}{ Myanmar } \\
\hline Nepal & Yes & Yes [82] \\
\hline \multicolumn{3}{|l|}{ Niger } \\
\hline Nigeria & Yes & \\
\hline Pakistan & Yes & Yes $[83,84]$ \\
\hline Rwanda & Yes & Yes [85] \\
\hline Sierra Leone & Yes & \\
\hline \multicolumn{3}{|l|}{ South Africa } \\
\hline Tanzania & Yes & \\
\hline Thailand & Yes & \\
\hline \multicolumn{3}{|l|}{ Uganda } \\
\hline Zambia & Yes & \\
\hline Zimbabwe & & \\
\hline
\end{tabular}

\section{Abbreviations}

AIM: Assessment and Improvement Matrix; ANC: Antenatal care; ASHA: Accredited social health activist; CHC: Community health committee; CHIS: Community health information system; CHW: Community health worker: COVID: Coronavirus disease; DHS: Demographic and health survey; FCHV: Female community health volunteer; iCCM: Integrated community case management; LMICs: Low- and middle-income countries; LQAS: Lot quality assurance sampling; NAP: National evaluation platform; PHC: Primary healthcare; RCT: Randomized controlled trial; TB:Tuberculosis; UNICEF: United Nations Children's Fund.

\section{Acknowledgements}

We are grateful to Sema Sgaier for thoughtful comments on this paper. We are also grateful for the financial support from the Bill \& Melinda Gates Foundation and the United States Agency for International Development that made this work possible. We also express our appreciation to members of the writing team that produced the book that served as a basis for this article (Developing and Strengthening Community Health Worker Programs at Scale: A Reference Guide and Case Studies for Program Managers and Policy Makers, available at:
https://www.mchip.net/sites/default/files/mchipfiles/CHW_ReferenceGuide_ sm.pdf).

\section{About this supplement}

This article has been published as part of Health Research Policy and Systems Volume 19, Supplement 3 2021: Community Health Workers at the Dawn of a New Era. The full contents of the supplement are available at https://healthpolicysystems.biomedcentral.com/articles/supplements/volume-19-suppl ement-3.

\section{Authors' contribution}

MK wrote the manuscripts based on the input from all authors. MK and HP further refined and finalized the manuscript. LC, DM, MB, and $\mathrm{SH}$ read and contributed to further revisions. All authors read and approved the final version.

Funding

Dr. Perry's contribution as well as publication expenses were supported in part by the Bill \& Melinda Gates Foundation (Investment ID OPP 1197181) and by the Maternal and Child Health Integrated Program (MCHIP) of Jhpiego, funded 
by the United States Agency for International Development. The funders had no role in the conduct of our work.

\section{Availability of data and materials}

Data sharing is not applicable to this article as no data sets were generated or analysed.

\section{Declarations}

Ethics approval and consent to participate

Not applicable.

\section{Consent for publication}

Not applicable.

\section{Competing interests}

The authors declare that they have no competing interests. The authors acknowledge that some of the work presented in this paper is previous work of some of the authors. We feel that this does not constitute a substantive conflict. It is a common practice for authors not to exclude references to their own work if they are relevant.

\section{Author details}

1 Department of Global Health, KIT Royal Tropical Institute, Amsterdam, The Netherlands. ${ }^{2}$ Crigler Consulting, LLC, Hillsborough, NC, USA. ${ }^{3}$ Department of Disease Control and Environmental Health, School of Public Health, Makerere University College of Health Sciences, Kampala, Uganda. ${ }^{4}$ Community Health Impact Coalition, New York, NY, USA. ${ }^{5}$ Department of Global Health and Health Systems Design, Icahn School of Medicine at Mount Sinai, New York, NY, USA. ${ }^{6}$ School of Public Health, University of Alberta, Edmonton, AB, Canada. ${ }^{7}$ Department of International Health, Johns Hopkins Bloomberg School of Public Health, Baltimore, MD, USA.

Received: 16 June 2021 Accepted: 17 June 2021

Published: 12 October 2021

\section{References}

1. Hodgins S, Lewin S, Glenton C, LeBan K, Crigler I, Musoke D, Kok M, Perry $\mathrm{H}$. Community health workers at the dawn of a new era: 1 . Introduction and tensions confronting programs. BMC Health Res Policy Syst. 2021. https://doi.org/10.1186/s12961-021-00752-8.

2. Afzal M, Pariyo G, Perry H Community health workers at the dawn of a new era: 2. Planning, coordination, and partnerships. BMC Health Res Policy Syst. 2021. https://doi.org/10.1186/s12961-021-00753-7.

3. Lewin S, Lehmann U, Perry H. Community health workers at the dawn of a new era: 3. Program governance. BMC Health Res Policy Syst. 2021. https://doi.org/10.1186/s12961-021-00749-3.

4. Masis L, Gichaga A, Lu C, Perry H. Community health workers at the dawn of a new era: 4. Program financing. BMC Health Res Policy Syst. 2021. https://doi.org/10.1186/s12961-021-00751-9

5. Glenton C, Javadi D, Perry H. Community health workers at the dawn of a new era: 5. Roles and tasks. BMC Health Res Policy Syst. 2021. https://doi. org/10.1186/s12961-021-00748-4.

6. Schleiff M, Aitken I, Perry H. Community health workers at the dawn of a new era: 6. Training. BMC Health Res Policy Syst. 2021. https://doi.org/10. 1186/s12961-021-00757-3.

7. Carpenter C, Musoke D, Crigler L, Perry H: Community health workers at the dawn of a new era: 7. Supervision. BMC Health Res Policy Syst. 2021. https://doi.org/10.1186/s12961-021-00754-6.

8. Colvin C, Hodgins S, Perry H. Community health workers at the dawn of a new era: 8 . Incentives and remuneration. BMC Health Res Policy Syst. 2021. https://doi.org/10.1186/s12961-021-00750-w.

9. LeBan K, Kok M, Perry H. Community health workers at the dawn of a new era: 9. CHWs' relationships with the health system and the community. BMC Health Res Policy Syst. 2021. https://doi.org/10.1186/ s12961-021-00756-4.

10. Cometto G, Ford N, Pfaffman-Zambruni J, Akl EA, Lehmann U, McPake B, Ballard M, Kok M, Najafizada M, Olaniran A, et al. Health policy and system support to optimise community health worker programmes: an abridged WHO guideline. Lancet Glob Health. 2018;6:e1397-404.

11. Ballard M. Community health workers: efficacy, taxonomy, and performance. Oxford: University of Oxford; 2016.

12. Perry HB, Crigler L, Hodgins S. Developing and Strengthening Community Health Worker Programs at Scale: A Reference Guide and Case Studies for Program Managers and Policy Makers [http://www.mchip.net/ sites/default/files/mchipfiles/CHW_ReferenceGuide_sm.pdf]. accessed 26 Apr 2021.

13. Perry HB, editor. Engaging Communities for Improving Mothers' and Children's Health: Reviewing the Evidence of Effectiveness in ResourceConstrained Settings. Edinburgh: Edinburgh University Global Health Society; 2017

14. Perry HB (ed.). Health for the People: National Community Health Programs from Afghanistan to Zimbabwe [https://pdf.usaid.gov/pdf_docs/ PA00WKKN.pdf.] accessed 26 Apr 2021.

15. WHO and UNICEF. Declaration of Alma-Ata [http://www.who.int/publi cations/almaata_declaration_en.pdf] accessed 26 Apr 2021.

16. WHO and UNICEF. Declaration of Astana [https://www.who.int/docs/ default-source/primary-health/declaration/gcphc-declaration.pdf] accessed 26 Apr 2021

17. WHO. WHO guideline on health policy and system support to optimize community health worker programmes [https://apps.who.int/iris/bitst ream/handle/10665/275474/9789241550369-eng.pdf?ua=1] accessed 26 Apr 2021.

18. Ghebreyesus TA. Address by Dr. Tedros Adhanom Ghebreyesus, DirectorGeneral [http://apps.who.int/gb/ebwha/pdf_files/WHA72/A72_3-en.pdf] accessed 26 Apr 2021.

19. World Health Assembly. Community health workers delivering primary health care: opportunities and challenges [http://apps.who.int/gb/ ebwha/pdf files/WHA72/A72 R3-en.pdf] Accessed 26 April 2021.

20. Wiah S, Subah M, Varpilah B, Waters A, Ly J, Ballard M, Price M, Panjabi R: Prevent, detect, respond: how community health workers can help in the fight against covid-19. BMJ 2020.

21. WHO and UNICEF. Community-based health care, including outreach and campaigns, in the context of the COVID-19 pandemic: interim guidance [https://www.who.int/publications/i/item/community-based-healthcare-including-outreach-and-campaigns-in-the-context-of-the-covid-19pandemic] accessed 26 Apr 2021

22. Community Health Impact Coalition. Priorities for the Global COVID-19 Response [https://docs.google.com/document/d/1 quxz5up90vWcbx b6HNHJ_vpsdhKP70pfixrROTla6Pc/edit?mc_cid=5b86482159\&mc_eid= 7813f0a466\#heading=h.dn0jtrmikw40] accessed 26 Apr 2021.

23. Haines A, de Barros EF, Berlin A, Heymann DL, Harris MJ. National UK programme of community health workers for COVID-19 response. Lancet. 2020;395:1173-5

24. Waters R. Community workers lend human connection to COVID-19 response. Health Aff (Millwood). 2020;39:1112-7.

25. Kok MC, Dieleman M, Taegtmeyer M, Broerse JE, Kane SS, Ormel H, Tijm MM, de Koning KA. Which intervention design factors influence performance of community health workers in low-and middle-income countries? A systematic review. Health Policy Plan. 2014;30:1207-27.

26. Kok MC, Kane SS, Tulloch O, Ormel H, Theobald S, Dieleman M, Taegtmeyer M, Broerse JEW, de Koning KAM. How does context influence performance of community health workers in low-and middle-income countries? Evidence from the literature. Health Res Policy Syst. 2015;13:13

27. Naimoli JF, Frymus DE, Wuliji T, Franco LM, Newsome MH. A Community Health Worker "logic model": towards a theory of enhanced performance in low-and middle-income countries. Hum Resour Health. 2014;12:56.

28. Agarwal S, Sripad P, Johnson C, Kirk K, Bellows B, Ana J, Blaser V, Kumar MB, Buchholz K, Casseus A. A conceptual framework for measuring community health workforce performance within primary health care systems. Hum Resour Health. 2019;17:86.

29. Schneider H, Lehmann U. From community health workers to community health systems: Time to widen the horizon? Health Syst Reform. 2016:2:112-8.

30. Hodgins S, Javadi D, Perry H: Chapter 15. Measurement and Data Use for Services Provided by Community Health Workers. In: Developing and Strengthening Community Health Worker Programs at Scale: A Reference Guide and Case Studies for Program Managers and Policymakers. 2014. 
31. Sheikh K, Gilson L, Agyepong IA, Hanson K, Ssengooba F, Bennett S. Building the field of health policy and systems research: framing the questions. PLoS Med. 2011;8:e1001073.

32. Community Health Worker Assessment and Improvement Matrix (CHW AIM): A Toolkit for Improving CHW Programs and Services [http://www. who.int/workforcealliance/knowledge/toolkit/50.pdf] Accessed 26 April 2021.

33. Community Health Impact Coalition. Updated Program Functionality Matrix for Optimizing Community Health Programs: Community Health Worker Assessment and Improvement Matix (CHW AIM) [https://wwW. unicef.org/media/58176/file] Accessed 26 April 2021.

34. WHO: Working together for health: the World Health Report. Geneva. Switzerland: World Health Organization; 2006. p. 2006.

35. Ballard M, Montgomery P. Systematic review of interventions for improving the performance of community health workers in low-income and middle-income countries. BMJ Open. 2017;7:014216.

36. Petesch P, Smulovitz C, Walton M: Evaluating empowerment: a framework with cases from Latin America. Measuring empowerment: Cross-disciplinary perspectives 2005:39-67.

37. Wellins RS, Bernthal P, Phelps M. Employee engagement: The key to realizing competitive advantage. Dev Dimen Int. 2005;5:1-31.

38. Hall MA, Dugan E, Zheng B, Mishra AK. Trust in physicians and medical institutions: what is it, can it be measured, and does it matter? Milbank Q. 2001:79:613-39.

39. Griffiths F, Babalola O, Brown C, de Kadt J, Malatji H, Thorogood M, Tseng $\mathrm{YH}$, Goudge J. Development of a tool for assessing quality of comprehensive care provided by community health workers in a community-based care programme in South Africa. BMJ Open. 2019;9:e030677.

40. Roberton T, Kasungami D, Guenther T, Hazel E. Monitoring iCCM: a feasibility study of the indicator guide for monitoring and evaluating integrated community case management. Health Policy Plan. 2016;31:759-66.

41. Thapa K, Dhital R, Rajbhandari S, Mishra S, Subedi S, Dotel BR, Vaidya S, Pande S, Tunnacliffe E-A, Makins A, Arulkumaran S. Improving postpartum family planning services provided by female community health volunteers in Nepal: a mixed methods study. BMC Health Serv Res. 2020;20:123.

42. Abimbola S, Molemodile SK, Okonkwo OA, Negin J, Jan S, Martiniuk AL. "The government cannot do it all alone": realist analysis of the minutes of community health committee meetings in Nigeria. Health Policy Plan. 2016;31:332-45.

43. José B, Manhiça I, Jones J, Mutaquiha C, Zindoga P, Eduardo I, Creswell J, Qin Z, Ramis O, Ramiro I. Using community health workers for facility and community based TB case finding: an evaluation in central Mozambique. PLOS ONE. 2020;15:e0236262.

44. O'Connor EC, Hutain J, Christensen M, Kamara MS, Conteh A, Sarriot E, Samba TT, Perry HB: Piloting a participatory, community-based health information system for strengthening community-based health services: findings of a cluster-randomized controlled trial in the slums of Freetown, Sierra Leone. J Glob Health 2019, 9.

45. DHS Program. DHS Model Questionnaire - Phase 8 (English, French) [https://dhsprogram.com/publications/publication-dhsq8-dhs-quest ionnaires-and-manuals.cfm] Accessed 26 April 2021.

46. UNICEF. MICS6 Tools [http://mics.unicef.org/tools] Accessed 26 April 2021.

47. Heidkamp R, Group NEPW: The National Evaluation Platform for Maternal, Newborn, and Child Health, and Nutrition: From idea to implementation. J Glob Health 2017, 7:020305.

48. Teklu A, Alemayehu Y: National Assessment of the Ethiopian Health Extension Program. Addis Ababa, Ethiopia: MERQ Consultancy PLC; 2019.

49. Edward A, Branchini C, Aitken I, Roach M, Osei-Bonsu K, Arwal SH. Toward universal coverage in Afghanistan: a multi-stakeholder assessment of capacity investments in the community health worker system. Soc Sci Med. 2015;145:173-83.

50. Aftab W, Rabbani F, Sangrasi K, Perveen S, Zahidie A, Qazi SA. Improving community health worker performance through supportive supervision: a randomised controlled implementation trial in Pakistan. Acta Paediatr. 2018;107(Suppl 471):63-71.

51. Whidden C, Kayentao K, Liu JX, Lee S, Keita Y, Diakite D, Keita A, Diarra S, Edwards J, Yembrick A, et al. Improving Community Health Worker performance by using a personalised feedback dashboard for supervision: a randomised controlled trial. J Glob Health. 2018;8:020418.
52. Shapira G, Kalisa I, Condo J, Humuza J, Mugeni C, Nkunda D, Walldorf J. Going beyond incentivizing formal health providers: Evidence from the Rwanda Community Performance-Based Financing program. Health Econ. 2018;27:2087-106.

53. Mwanza M, Zulu J, Topp SM, Musonda P, Mutale W, Chilengi R. Use of Lot quality assurance sampling surveys to evaluate community health worker performance in rural Zambia: a case of Luangwa district. BMC Health Serv Res. 2017; 17:279.

54. Smittenaar $P$, Ramesh BM, Jain M, Blanchard J, Kemp H, Engl E, Isac S, Anthony J, Prakash R, Gothalwal V, et al. Bringing greater precision to interactions between community health workers and households to improve maternal and newborn health outcomes in India. Glob Health Sci Pract. 2020:8:358-71.

55. Gallup. Employee Engagement: The Key to Realizing Competitive Advantage [https://www.scribd.com/document/23973862/Employee-Engag ement-The-Key-to-Realizing-Competitive-Advantage] Accessed 26 April 2021

56. Engl E, Sgaier SK. CUBES: A practical toolkit to measure enablers and barriers to behavior for effective intervention design. Gates Open Res. 2019;3:886.

57. Vallières F, Kok M, Mahmud I, Sarker M, Jeacocke P, Karuga R, Limato L, Kea AZ, Chikaphupha K, Sidat M, et al. Measuring motivation among closeto-community health workers: developing the CTC Provider Motivational Indicator Scale across six countries. Hum Resour Health. 2020;18:54.

58. Kane S, Kok M, Ormel H, Otiso L, Sidat M, Namakhoma I, Nasir S, Gemechu D, Rashid S, Taegtmeyer M: Limits and opportunities to community health worker empowerment: a multi-country comparative study. Soc Sci Med 2016.

59. Vareilles G, Marchal B, Kane S, Petric T, Pictet G, Pommier J. Understanding the motivation and performance of community health volunteers involved in the delivery of health programmes in Kampala, Uganda: a realist evaluation. BMJ Open. 2015;5:e008614.

60. Post D, Agarwal S, Venugopal V: Rapid feedback: the role of community scorecards in improving service delivery. 2014.

61. Scott K, Beckham S, Gross M, Pariyo G, Rao KD, Cometto G, Perry HB. What do we know about community-based health worker programs? A systematic review of existing reviews on community health workers. Hum Resour Health. 2018;16:39.

62. Lewis J, LeBan K, Solomon R, Bisrat F, Usman S, Arale A: The critical role and evaluation of community mobilizers in polio eradication in remote settings in Africa and Asia. Global Health: Science and Practice 2020, https://doi.org/10.9745/GHSP-D-20-00024. accessed 26 Apr 2021.

63. Lewis M. Pettersson G. Governance in health care delivery: Raising performance. [http://documents.worldbank.org/curated/en/792741468330936 271/Governance-in-health-care-delivery-raising-performance] accessed 26 Apr 2021.

64. Vallières F, Hyland P, McAuliffe E, Mahmud I, Tulloch O, Walker P, Taegtmeyer M. A new tool to measure approaches to supervision from the perspective of community health workers: a prospective, longitudinal, validation study in seven countries. BMC Health Serv Res. 2018;18:806.

65. Kok MC, Kane SS, Tulloch O, Ormel H, Theobald S, Dieleman M, Taegtmeyer M, Broerse JE, de Koning KA. How does context influence performance of community health workers in low- and middle-income countries? Evidence from the literature. Health Res Policy Syst. 2015;13:13.

66. Marston C, Arjyal A, Maskey S, Regmi S, Baral S. Using qualitative evaluation components to help understand context: case study of a family planning intervention with female community health volunteers (FCHVs) in Nepal. BMC Health Serv Res. 2020;20:1-10.

67. Bergstrom A, Skeen S, Duc DM, Blandon EZ, Estabrooks C, Gustavsson P, Hoa DT, Kallestal C, Malqvist M, Nga NT, et al. Health system context and implementation of evidence-based practices-development and validation of the Context Assessment for Community Health (COACH) tool for low- and middle-income settings. Implement Sci. 2015;10:120.

68. Kitson A, Harvey G, McCormack B. Enabling the implementation of evidence based practice: a conceptual framework. Qual Health Care. 1998;7:149-58.

69. Flora OC, Margaret K, Dan K: Perspectives on utilization of community based health information systems in Western Kenya. Pan Afr Med J 2017, 27.

70. Regeru RN, Chikaphupha K, Bruce Kumar M, Otiso L, Taegtmeyer M. 'Do you trust those data?'-a mixed-methods study assessing the quality of 
data reported by community health workers in Kenya and Malawi. Health Policy Plan. 2020;35:334-45.

71. Yourkavitch J, Prosnitz D, Herrera S: Data quality assessments stimulate improvements to health management information systems: evidence from five African countries. J Glob Health 2019, 9.

72. Biemba G, Chiluba B, Yeboah-Antwi K, Silavwe V, Lunze K, Mwale RK, Russpatrick S, Hamer DH. A mobile-based community health management information system for community health workers and their supervisors in 2 districts of Zambia. Glob Health. 2017;5:486-94.

73. Mengesha W, Steege R, Kea A, Theobald S, Datiko D. Can mHealth improve timeliness and quality of health data collected and used by health extension workers in rural Southern Ethiopia? J Public Health. 2018:40:74-86.

74. Maher D, Cometto G. Research on community-based health workers is needed to achieve the sustainable development goals. Bull World Health Organ. 2016;94:786.

75. George AS, LeFevre AE, Schleiff M, Mancuso A, Sacks E, Sarriot E: Hubris, humility and humanity: expanding evidence approaches for improving and sustaining community health programmes. BMJ Glob Health 2018, 3.

76. Agarwal S, Kirk K, Sripad P, Bellows B, Abuya T, Warren C. Setting the global research agenda for community health systems: literature and consultative review. Hum Resour Health. 2019;17:22.

77. McCollum R, Gomez W, Theobald S, Taegtmeyer M. How equitable are community health worker programmes and which programme features influence equity of community health worker services? A systematic review. BMC Public Health. 2016;16:419.

78. Vaughan K, Kok MC, Witter S, Dieleman M. Costs and cost-effectiveness of community health workers: evidence from a literature review. Hum Resour Health. 2015;13:71.

79. Macinko J, Guanais FC, de Fatima M, de Souza M. Evaluation of the impact of the Family Health Program on infant mortality in Brazil, 1990-2002. J Epidemiol Commun Health. 2006;60:13-9.
80. Agarwal S, Curtis SL, Angeles G, Speizer IS, Singh K, Thomas JC. The impact of India's accredited social health activist (ASHA) program on the utilization of maternity services: a nationally representative longitudinal modelling study. Hum Resour Health. 2019;17:68.

81. $\mathrm{MOH} /$ Kenya. Evaluation Report of the Implementation of the Community Health Strategy in Kenya, October 2010 [https://www.unicef.org/ evaldatabase/files/14_2010_HE_002_Community_Strategy_Evaluation_ report_October_2010.pdf] accessed 26 Apr 2021.

82. Female Community Health Volunteer National Survey Report 2014 [https://www.advancingpartners.org/sites/default/files/sites/default/ files/resources/fchv_2014_national_survey_report_a4_final_508_0.pdf\# overlay-context=female-community-health-volunteer-national-surveyreport-2014] accessed 26 Apr 2021.

83. Oxford Policy Management: Lady Health Worker Programme: External Evaluation of the National Programme for Family Planning and Primary Health Care 1999-2002: Final Report. Oxford Policy Management; 2002.

84. Oxford Policy Management: External Evaluation of the National Programme for Family Planning and Primary Health Care: Lady Health Worker Programme. Summary of Results. pp. 41. Oxford, U.K.: Canadian International Development Agency; 2009:41.

85. Ingenuity Ltd.: Rwanda's Community Health Program (1995-2015): 20 Years of Building Healthier Communities. Kigali, Rwanda: Rwanda Governance Board; 2015

\section{Publisher's Note}

Springer Nature remains neutral with regard to jurisdictional claims in published maps and institutional affiliations.
Ready to submit your research? Choose BMC and benefit from:

- fast, convenient online submission

- thorough peer review by experienced researchers in your field

- rapid publication on acceptance

- support for research data, including large and complex data types

- gold Open Access which fosters wider collaboration and increased citations

- maximum visibility for your research: over 100M website views per year

At BMC, research is always in progress.

Learn more biomedcentral.com/submissions 